\title{
PENANGGULANGAN COVID SEBAGAI SARANA UNTUK MENCIPTAKAN KESEHATAN MASYARAKAT DI LINGKUNGAN DESA JOYOSUKO METRO
}

\author{
Ikhsan Maksum \\ Fakultas Ekonomi, UIN Maulana Malik Ibrahim Malang \\ ikhsan.maksum@uin-malang.ac.id
}

\section{Info Artikel}

\section{Riwayat Artikel:}

Diterima: Januari 2021

Direvisi: Februari 2021

Diterbitkan: Maret 2021

\section{Keywords:}

Joyosuko Metro Village Qualitative Descriptive

\begin{abstract}
The aim of the KKM is to improve the abilities and insights of students as a means of living in society. This year's implementation for our group located in Joyosuko Metro Village is a village in the Malang District, East Java Province. Joyosuko Metro Village is a sub-district center that offers a natural environment and community harmony. This Student Work Lecture (KKM) this year, invites students to research about 5 aspects offered by the campus to the community, including: 1 . Education 2. Health 3. Information Technology 4. Religious and 5. Natural Resources or the potential possessed by the community itself, whether from the agricultural, plantation or livestock economy. The main purpose of this activity is to hone the knowledge and experience of students who have gained in the lecture bench, and this activity can help students to go directly to the community. The research method uses a case study with a descriptive qualitative approach. The data collection techniques carried out by researchers are documentation, observation and interviews with participants to obtain valid data. The results of activities in the form of making a village profile and adding to the contents that are considered capable of lifting the village and looked at by the central government. Creating an Penanggulangan covid-19is another excellent program for Joyosuko Metro Village, the aim is to beautify and make the village hall an environmentally friendly office.
\end{abstract}

Copyright (C) 2021 JRCE. All rights reserved.

\author{
Korespondensi: \\ Ikhsan Maksum, \\ UIN Maulana Malik Ibrahim Malang, \\ Jl. Gajayana No. 50 Malang, Jawa Timur, Indonesia 65144 \\ ikhsan.maksum@uin-malang.ac.id
}

\section{PENDAHULUAN}

KKM UIN Mengabdi di Desa Joyosuko Metro, Kecamatan Joyosuko Metro, Kabupaten Malang periode 2019/2020. Desa Joyosuko Metro merupakan desa yang terletak di Kabupaten Malang dengan keasrian wilayahnya. Meskipun Desa Joyosuko Metro merupakan pusat Kecamatan Joyosuko Metro, namun keguyupan desanya masih terasa. Kuliah Kerja Mahasiswa (KKM) adalah suatu kegiatan pengabdian kepada masyarakat yang telah termasuk pada Tri Darma Perguruan Tinggi pada point ke-3, yaitu pengabdian kepada masyarakat. Tujuan yang paling utama pada kegiatan ini adalah untuk mengasah pengetahuan dan pengalaman mahasiswa yang telah diperoleh selama beberapa semester dibangku perkuliahan, dan kegiatan ini dirasa sangat membantu 
mahasiswa yang selanjutnya akan terjun langsung ke masyarakat masing-masing daerah setelah dari Perguruan Tinggi.

Kuliah Kerja Mahasiswa (KKM) pada tahun ini, mengajak mahasiswa untuk kepada sebuah penelitian tentang 5 aspek yang ditawarkan oleh kampus kepada masyarakat, antara lain yaitu: 1. Pendidikan 2. Kesehatan 3. Teknologi Informatika 4. Keagamaan dan 5. Sumber Daya Alam atau potensi yang dimiliki pada masyarakat itu sendiri, entah dari ekonomi pertanian, perkebunan, maupun peternakan. Penelitian ini juga mengajak kepada mahasiswa mampu memberikan suatu hasil dari penelitian yang berkesinambungan untuk memajukan masyarakat dan Desa.

Program unggulan di Desa Joyosuko Metro itu sendiri, yaitu Teknologi Informatika yang dimana berisi tentang pembuatan profil desa dan menambahkan dengan konten-konten yang dirasa mampu mengangkat desa tersebut dan dilirik oleh pemerintah pusat. Membuat Penanggulangan Covid-19 merupakan program unggulan lain untuk di Desa Joyosuko Metro, tujuannya adalah untuk memperindah dan membuat balai desa menjadi kantor yang ramah lingkungan dan peduli kesehatan. Hal ini diharapkan memberi rasa nyaman dan aman kepada pegawai desa yang bekerja disana serta masyarakat desa atau tamu yang berkunjung di kantor desa tersebut.

Beberapa tanaman yang akan diletakkan disana diantaranya bunga paku ekor kuda dengan batangnya yang tidak bercabang sehingga mudah ditata dan sangat cocok untuk diletakkan diteras maupun di dalam ruangan. Selain itu warna hijaunya bisa menyegarkan mata bagi pegawai desa, khususnya bagi mereka yang setiap hari harus berhadapan dengan layar komputer. Selain tanaman hias untuk meja ada juga tanaman gantung yang digantungkan pada kedua atap teras kantor desa. Tanaman yang digantung pada kedua atap teras ini memiliki bunga berwarna terang yang memberi efek positif bagi mereka pengguna akses utama kantor desa. Letaknya yang berada dipintu masuk seakan memberi sapa bahagia bagi setiap orang yang memandangnya, begitupun saat keluar dari kantor desa.

\section{METODE PENELITIAN}

Metode penelitian menggunakan studi kasus dengan pendekatan melalui descriptive qualitative. Adapaun Teknik pengumpulan data yang dilakukan oleh peneliti yaitu dokumentasi, observasi dan wawancara dengan partisipan untuk memperoleh data yang valid. Data yang dimaksud adalah data yang terkait dengan Penanganan Covid-19 dan Moderasi Beragama. Wawancara yang dilakukan oleh peneliti adalah wawancara terbuka, yang artinya pertanyaan dapat berubah sesuai dengan kebutuhan di lapangan. Hal ini selaras dengan Stake (1995) yang menyarankan desain penelitian yang fleksibel di mana peneliti dapat merubah proses yang sudah ada meskipun terjadi pada proses penelitian. Peneliti juga menggunakan triangulasi untuk menguatkan bukti-bukti penelitian Yin (2002). Triangulasi juga dapat berfungsi sebagai prbaikan validitas dan reliabilitas dalam sebuah penelitian dengan metode kualitatif.

\section{HASIL DAN PEMBAHASAN}

Pada hari senin pagi, tepatnya tanggal 30 Desember 2019 di Kantor Desa Joyosuko Metro Kecamatan Joyosuko Metro Kabupaten Malang. Kelompok 143 KKM UIN Mengabdi telah menyelenggarakan program kerja Moderasi Beragama dan Penanggulangan Covid-19. Salah satu program yang merupakan permintaan dari kantor Desa Joyosuko Metro ini yang akan didesainkan bertema Penanggulangan Covid-19 yang sarat akan protokol kesehatan. Penanggulangan covid-19 adalah salah satu program kerja yaitu mendesain kantor desa agar lebih ramah lingkungan dengan menambahkan beberapa tumbuh-tumbuhan serta melakukan beberapa perubahan sedikit dibeberapa titik. Program ini sendiri berguna agar kantor desa terlihat lebih indah dan tentu saja untuk lebih ramah lingkungan dari sebelumnya, sesuai dengan nama program kerja kami yaitu Penanggulangan covid-19. Penanggulangan covid-19 menciptakan suatu kantor yang ramah lingkungan dengan cara membeli beberapa bunga-bunga yang menghiasi ruang utama kantor desa dan juga beberapa bambu air/ekor paku kuda yang diletakkan di depan kantor desa dan ada juga rak dinding yang terbuat dari kayu yang di letakkan di bawah TV yang mempunyai kegunaan untuk menaruh beberapa barang dan beberapa hiasan, dengan memilih barang-barang yang terbuat dari kayu bertujuan mengurangi penggunaan bahan plastik dikantor jadi kami memilih bahan dari kayu, selain mengurangi penggunaan bahan plastik penggunaan kayu juga terkesan bagus dan elegan untuk digunakan dikantor dan juga memasang Hand Sanitizer serta menyediakan tempat cuci tangan untuk tamu yang berkunjung.

Pelaksanaan program kerja ini dilaksana dengan menggambar kembali denah kantor desa yang sudah ada oleh anggota kelompok KKM 143, setelah selesai menggambar dan mendesain serta melakukan perubahan sedikit di beberapa titik dilanjutkan dengan konsultasi dengan perangkat desa terkait desain Penanggulangan covid-19 untuk mendapat persetujuan dari perangkat desa dan segera melakukan langkah selanjutnya. Pelaksanaan program selanjutnya dengan membeli beberapa bahan dan kebutuhan untuk memperlancar 
pelaksaan program kerja ini, demi mendapatakan beberapa pohon dan bunga, kami akhirnya menuju Splendid, di sinilah kami mendapatkan beberapa tanaman yang berguna memperindah kantor lalu dilanjutkan dengan membeli beberapa tambahan barang yang terbuat dari kayu dan beberapa pot bunga yang terbuat dari tanah untuk menempatkan beberapa tumbuhan.

Ketika semua sudah didapatkan maka kami melanjutkan dengan konsultasi tentang progres yang sudah kami lakukan kepada perangkat desa. Setelah sesuai dengan instruksi dan perancangan program kami sebelumnya, maka kami melanjutkan tahap terakhir yaitu pemasangan dan penempatan tanaman di beberapa titik sesuai dengan desain yang sudah kami buat. Selain tanaman hias untuk meja, ada juga tanaman gantung yang digantungkan pada kedua atap teras kantor desa. Tanaman yang digantung pada kedua atap teras ini memiliki bunga berwarna terang yang memberi efek positif bagi mereka pengguna akses utama kantor desa. Letaknya yang berada dipintu masuk seakan memberi sapa bahagia bagi setiap orang yang memandangnya, begitupun saat keluar dari kantor desa.

Adapun faktor utama yang mendukung terlaksananya program ini adalah dana yang diberikan dari pihak desa. Pihak desa sangat antusias dan mendukung program Penanggulangan covid-19 ini. Dana yang diberikan dari pihak desa sejumlah Rp 2.140.000,00. Dana ini sepenuhnya digunakan untuk memenuhi perlengkapan pelaksanaan program Penanggulangan covid-19 berupa tanaman gantung dan tanaman hias yang diletakkan dibeberapa sudut ruangan beserta perlengkapan pendukung lainnya.

\section{KESIMPULAN}

Pelaksanaan Kuliah Kerja Mahasiswa (KKM) di Desa Joyosuko Metro, Kecamatan Joyosuko Metro, Kota Malang dimulai pada tanggal 21 Desember 2020 dan berakhir pada 21 Januari 2021. Semua program yang disusun telah dijalankan dengan baik dan mendapat dukungan dari perangkat desa dan terutama dari masyarakat sekitar walaupun kenyataannya dalam kegiatan tersebut terdapat beberapa kendala yang harus dihadapi oleh peserta Kuliah Kerja Mahasiswa (KKM).

Perwujudan program kerja Kuliah Kerja Mahasiswa (KKM) yaitu program Penanggulangan covid-19 karena sesuai dengan apa yang dibutuhkan di Desa Joyosuko Metro, Kecamatan Joyosuko Metro, Kabupaten Malang, yaitu memberikan nuansa sejuk pada lingkungan Kantor Desa Joyosuko Metro. Kepala Desa Joyosuko Metro, Bapak Widiarto menginginkan perangkat desa dapat melakukan pekerjaan mereka dengan santai dan segar serta menyambut kedatangan masyarakat dengan nuansa sejuk yang diciptakan dari pembangunan Penanggulangan covid-19 tersebut. Desain Project Penanggulangan covid-19. Hasil dari program kerja Penanggulangan covid-19 memberikan suasana baru dan menambah nilai estetika pada bangunan Kantor Desa Joyosuko Metro.

\section{DAFTAR PUSTAKA}

[1] Stake, R. (1995). The art of case research. Thousand Oaks, CA: Sage Publications. doi: 10.2307/329758

[2] Yin, Robert. K. (2002). Case Study Research: Design and methods (2rd ed.). Thousand Oaks, CA: Sage

[3] S. S. Arifin, M. R. Syukri, and M. I. D. Kalamang, "Program IPTEKS bagi Wilayah (IbW) Kecamatan Kota Barat Kota Gorontalo," Gorontalo, 2015. 